\title{
Hyper-Adrenocorticotropinemia in a Patient with Addison's Disease after Treatment with Corticosteroids
}

\author{
Kazuhiko Sugiyama, Mamoru Kimura, Takashi Abe, Yoshihiro Ikezawa, Hideo ManaKa, \\ Keiichi Yamatani, Makoto Tominaga, Hideo Sasaki and Tatsuo Misawa*
}

\begin{abstract}
A 40-year-old man with Addison's disease due to adrenal tuberculosis retained high levels of adrenocorticotropic hormone (ACTH) after conventional hydrocortisone replacement. Plasma ACTH levels were completely suppressed by usual replacement with hydrocortisone (20 mg at 8:00 and $10 \mathrm{mg}$ at 21:00) but rebounded to abnormally high levels the following morning. Administration of $2 \mathrm{mg}$ or $8 \mathrm{mg}$ of dexamethasone suppressed ACTH and cortisol. Magnetic resonance imaging of the brain showed a low-intensity lesion of the pituitary gland. Pituitary hyperplasia or microadenoma with preserved regulation of ACTH was considered to be the cause of the high plasma ACTH levels. The combination of hydrocortisone and dexamethasone reduced plasma ACTH levels.
\end{abstract}

(Internal Medicine 35: 555-559, 1996)

Key words: adrenal tuberculosis, pituitary hyperplasia, pituitary adenoma

\section{Introduction}

Adrenocorticotropic hormone (ACTH)-producing adenoma secondary to Addison's disease is very rare compared with Nelson's syndrome after bilateral adrenectomy (1-9). In almost all cases, ACTH-producing hyperplasia or adenoma manifested after several years of conventional steroid replacement. Here, we describe a case already demonstrating inappropriate secretion of ACTH when he was diagnosed with Addison's disease. Magnetic resonance imaging of the pituitary gland was performed. Prolonged adrenal insufficiency for up to ten years may lead to hyperplasia or microadenoma of the pituitary cells.

\section{Case Report}

A 40-year-old man who had complained of nausea, vomiting and anorexia for two weeks visited Sagae City Hospital and was admitted to the hospital that day. At 21 years of age, he had been admitted for caries of the left 4 th toe and was treated for tuberculosis for 3 months. When he was 34 years old, he was also admitted for caries of the lumbar spine and was treated for 3 months. He has been aware of systemic pigmentation for about 10 years. On physical examination, his skin including the mucosal membrane was deeply pigmented. Supine blood pressure was $110 / 80 \mathrm{mmHg}$. Initial laboratory examination showed hyponatremia, hyperkalemia, anemia, hypoglycemia and leukocytosis with neutrophilia (Table 1). No tubercle bacillus was detected in the culture of sputa and gastric juice. Abdominal X-ray showed bilateral abdominal calcifications and computed tomography revealed bilateral enlarged calcified adrenal glands (Fig. 1). Although plasma cortisol levels were below normal and urinary excretion of 17 hydroxycorticosteroid (17 OHCS) was below normal, ACTH was elevated $(610 \mathrm{pg} / \mathrm{ml})$. He was diagnosed with Addison's disease due to adrenal tuberculosis, and he was treated with hydrocortisone. His clinical features and laboratory data improved rapidly except for ACTH. Even after replacement with $20 \mathrm{mg}$ hydrocortisone once a day in the morning, ACTH levels remained high.

He was transferred to Yamagata University Hospital to investigate the cause of high ACTH. Plasma ACTH levels were persistently suppressed to less than $10 \mathrm{pg} / \mathrm{ml}$ by administration of $2 \mathrm{mg}$ or $8 \mathrm{mg}$ dexamethasone (divided into 4 times a day, respectively). Plasma levels of cortisol were suppressed to 1.3 $\mu \mathrm{g} / \mathrm{dl}$ either by $2 \mathrm{mg}$ or $8 \mathrm{mg}$ dexamethasone. Suppression of ACTH by $20 \mathrm{mg}$ (once a day) hydrocortisone was insufficient (Fig. 2). From the results of the dexamethasone-suppression test, we increased the daily doses of hydrocortisone to $30 \mathrm{mg}$ (20 $\mathrm{mg}$ at 8:00 and $10 \mathrm{mg}$ at 21:00). Subsequently, $17 \mathrm{OHCS}$ increased to $14.3 \mathrm{mg} / \mathrm{day}$, indicating that hydrocortisone replacement was sufficient. However, in addition to ACTH (665

From the Third Department of Internal Medicine, Yamagata University School of Medicine, Yamagata and *Sagae City Hospital, Sagae Received for publication August 15, 1995; Accepted for publication May 1, 1996

Reprint requests should be addressed to Dr. Kazuhiko Sugiyama, the Third Department of Internal Medicine, Yamagata University School of Medicine, 2-2-2 Iida-Nishi, Yamagata 990-23 
Table 1. Laboratory Data on Admission.

\begin{tabular}{|c|c|c|c|}
\hline White blood cell count $(/ \mu \mathrm{l})$ & $\underline{10,400}$ & Blood urea nitrogen $(\mathrm{mg} / \mathrm{dl})$ & 29.4 \\
\hline Neutrophil (\%) & $\underline{76}$ & Creatinine $(\mathrm{mg} / \mathrm{dl})$ & $\overline{1.71}$ \\
\hline Eosinophil (\%) & $\overline{2}$ & Uric acid (mg/dl) & 6.5 \\
\hline Basophil (\%) & 1 & Glucose (mg/dl) & $\underline{64}$ \\
\hline Lymphocyte (\%) & 18 & Sodium $(\mathrm{mEq} / \mathrm{l})$ & $1 \overline{29}$ \\
\hline Monocyte $(\%)$ & 3 & Potassium $(\mathrm{mEq} / l)$ & 6.4 \\
\hline Red blood cell count $\left(10^{5} / \mu \mathrm{l}\right)$ & $\underline{379}$ & Chloride $(\mathrm{mEq} / \mathrm{l})$ & $\overline{99}$ \\
\hline Hemoglobin $(\mathrm{g} / \mathrm{dl})$ & $\overline{10.3}$ & Calcium (mg/dl) & 9.9 \\
\hline Hematocrit $(\%)$ & $\overline{30.6}$ & Triglyceride $(\mathrm{mg} / \mathrm{dl})$ & 103 \\
\hline \multirow[t]{2}{*}{ Platelet $\left(10^{4} / \mu \mathrm{l}\right)$} & $\overline{24.1}$ & Total cholesterol (mg/dl) & 149 \\
\hline & & High-density lipoprotein cholesterol (mg/dl) & 46 \\
\hline Total protein $(\mathrm{g} / \mathrm{dl})$ & 8.2 & & \\
\hline Albumin $(\mathrm{g} / \mathrm{dl})$ & 4.7 & C-reactive protein $(\mathrm{mg} / \mathrm{dl})$ & $<0.2$ \\
\hline Total bilirubin (mg/dl) & 1.0 & Erythrocyte sedimentation rate & $5 / 11$ \\
\hline Direct bilirubin (mg/dl) & 0.3 & & \\
\hline Aspartate aminotransferase (IU) & 33 & \multicolumn{2}{|l|}{ Adrenocorticotropic hormone $(\mathrm{pg} / \mathrm{ml}) 610(<100)$} \\
\hline Alanine aminotransferase (IU) & 36 & Cortisol $(\mu \mathrm{g} / \mathrm{dl}) \quad 6.3 \overline{(4.0}$ & $18.3)$ \\
\hline Lactic dehydrogenase (IU) & 245 & Aldosterone $(\mathrm{pg} / \mathrm{ml})$ & $-240)$ \\
\hline Alkaline phosphatase (IU) & 226 & 17-hydroxycorticosteroid (mg/day) $\overline{7} .1(3.1-$ & $-8.7)$ \\
\hline Cholinesterase (IU) & 171 & 17-ketosteroid (mg/day) $\quad 2.3(4.2-$ & $12.4)$ \\
\hline$\gamma$-glutamyltranspeptidase (IU) & 31 & & \\
\hline Amylase (IU) & 109 & & \\
\hline Creatine phosphokinase (IU) & 122 & & \\
\hline
\end{tabular}

Underlined data indicate abnormal findings

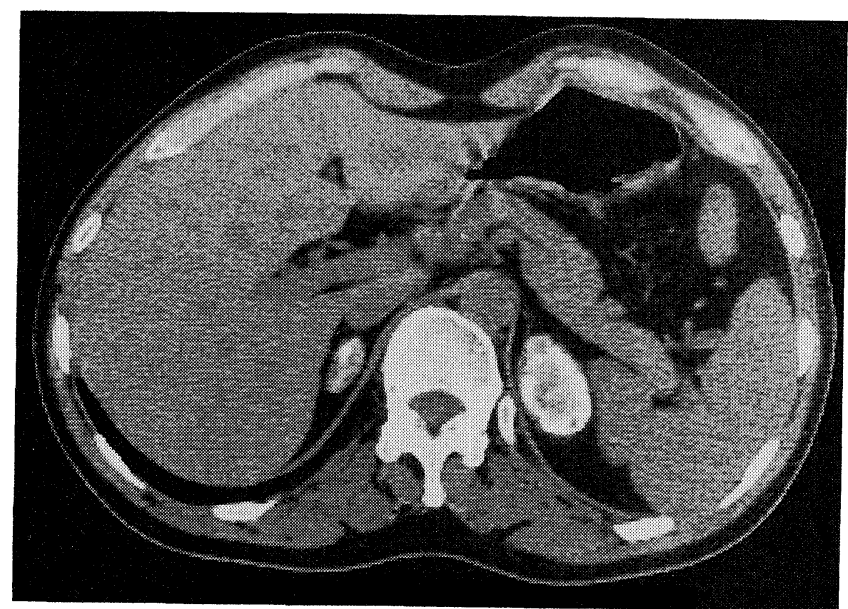

Figure 1. Abdominal computed tomography showing bilateral calcified adrenal glands.

$\mathrm{pg} / \mathrm{ml}), \beta$-endorphin $(93 \mathrm{pg} / \mathrm{ml})$ remained high in the morning (6:00). Magnetic resonance imaging (MRI) of the brain showed swelling of the right side of the pituitary gland, which was not enhanced by gadolinium-diethylene triamine penta-acetic acid (Gd-DTPA) (Fig. 3). Daily profiles of ACTH under $30 \mathrm{mg}$ hydrocortisone replacement showed that ACTH was low during the day, but high the next morning (Fig. 2b). Stimulation tests for several hormones were performed the previous morn- ing without $20 \mathrm{mg}$ hydrocortisone replacement. ACTH and cortisol did not respond to the administration of corticotropin releasing factor (CRF) (100 $\mu$ g, intravenous injection) (Fig. 2c). Arginine (30 g, intravenous infusion for 30 minutes), luteinizing hormone releasing hormone (LHRH) $(100 \mu \mathrm{g}$, intravenous injection) and thyrotropin releasing hormone (TRH) $(500 \mu \mathrm{g}$, intravenous injection) loading tests showed normal responses of pituitary hormones except for a low response of folliclestimulating hormone (FSH) (Fig. 4). The results suggest that the suppressive effect of hydrocortisone on ACTH secretion was shorter than usual. This short duration of ACTH suppression could be a characteristic of the pituitary gland in which there appeared hyperplasia or microadenoma and was probably due to a slow degradation of ACTH or to reduced sensitivity in this pituitary, compared to a normal pituitary.

Administration of $20 \mathrm{mg}$ hydrocortisone at $8: 00$ and $0.25 \mathrm{mg}$ dexamethasone (having a longer half-life of over 200 minutes), at 21:00 instead of $10 \mathrm{mg}$ hydrocortisone (having a shorter half life of approximately 80 minutes), suppressed ACTH to $118 \mathrm{pg} /$ $\mathrm{ml}$ the next morning (6:00). However, hyponatremia in the morning was induced after the administration of dexamethasone. To prevent hyponatremia, $0.05 \mathrm{mg}$ fludrocortisone acetate was administered at 21:00, and thereafter the serum sodium level was restored to $140 \mathrm{mEq} / l$. There was no significant change in MRI of the brain after the replacement therapy for 6 months but, systemic pigmentation faded during therapy. 

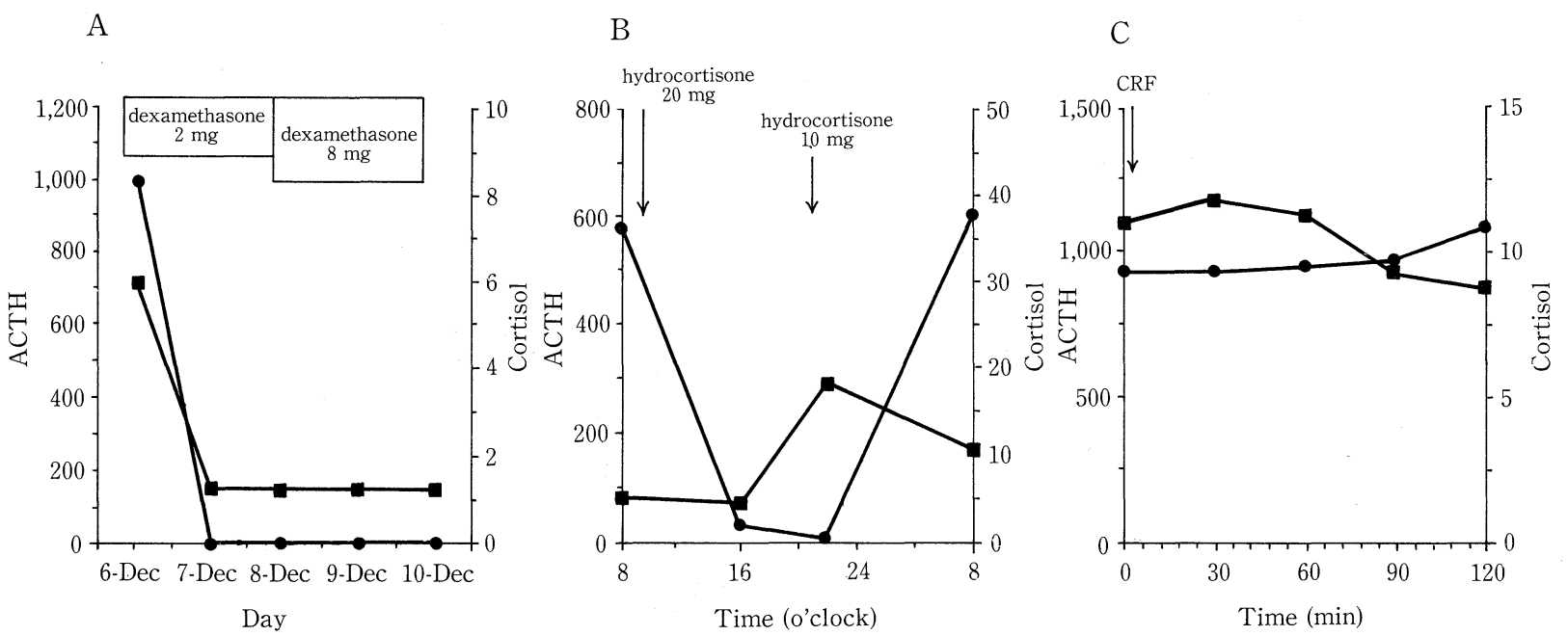

Figure 2. A) Dexamethasone suppression test; $2 \mathrm{mg}$ and $8 \mathrm{mg}$ dexamethasone suppressed ACTH and cortisol. B) Daily profile of ACTH and cortisol under hydrocortisone replacement. C) Corticotropin releasing factor (CRF) loading test; ACTH and cortisol did not respond to CRF. Closed circle indicates ACTH. Closed square indicates cortisol.

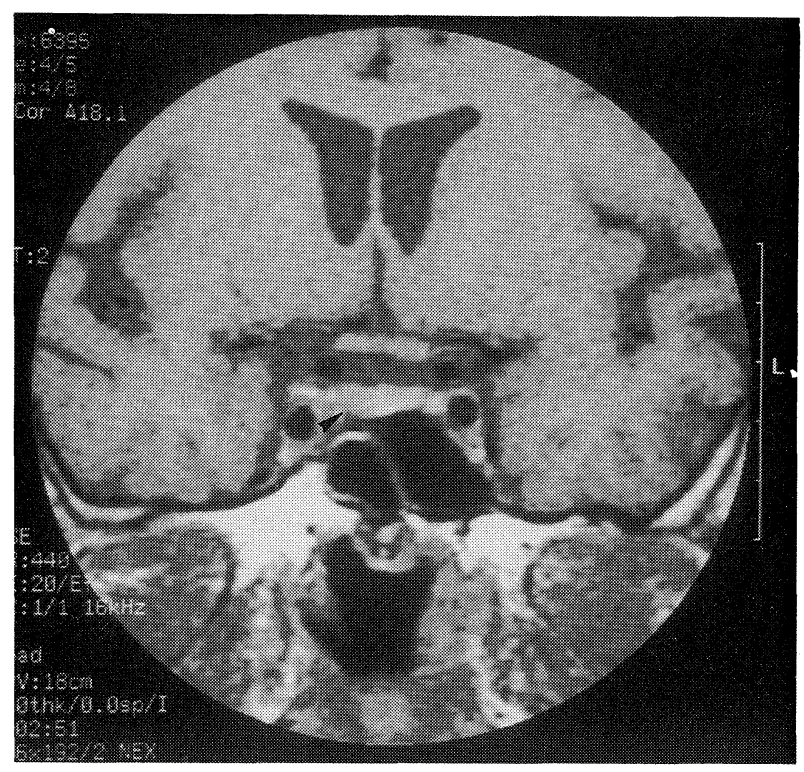

a

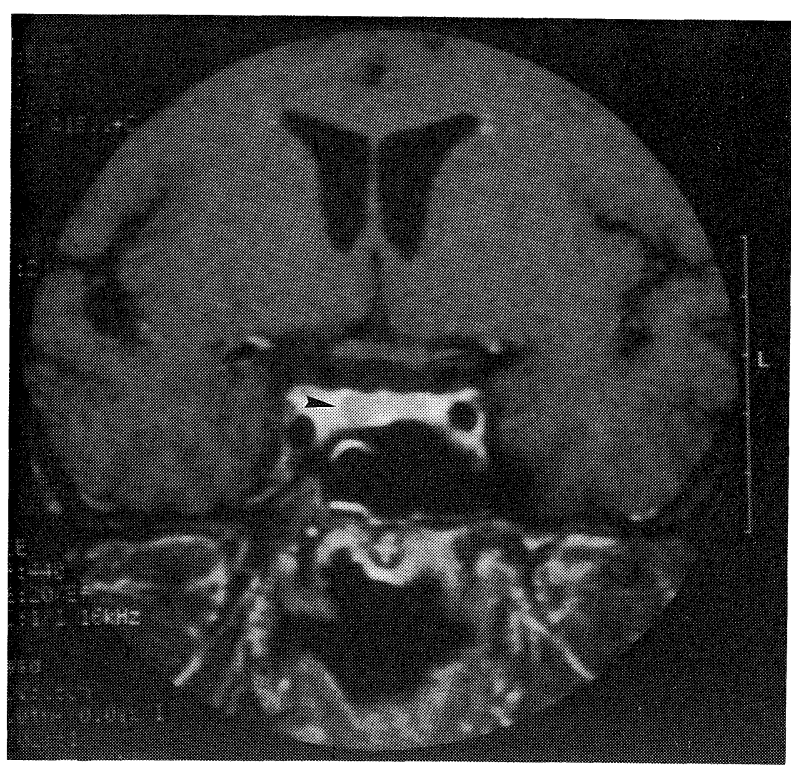

$\mathrm{b}$

Figure 3. a) Magnetic resonance imaging of the brain showing swelling of right pituitary gland (arrowhead) (T1 emphasized). b) Gd-DTPA enhancement of MRI. The lesion was not enhanced by Gd-DTPA (arrowhead) (T1 emphasized).

\section{Discussion}

We report a case of hypersecretion of ACTH after conventional hydrocortisone replacement in patients with Addison's disease. Urinary excretion of 17 OHCS was $14.3 \mathrm{mg} /$ day when $30 \mathrm{mg}$ hydrocortisone was given. This suggested hydrocortisone replacement was sufficient. Increased levels of ACTH and $\beta$-endorphin during conventional treatment with hydrocorti- sone and suppression of ACTH levels by dexamethasone treatment indicated that substances affecting the radio immunoassay (RIA) were deniable. Therefore, ACTH-producing hyperplasia or adenoma secondary to Addison's disease was suspected. ACTH-producing adenoma in Addison's disease is very rare (1-9).

Two hypothesis have been suggested to explain the pathogenesis of the hyperplasia or adenoma of the pituitary 
A

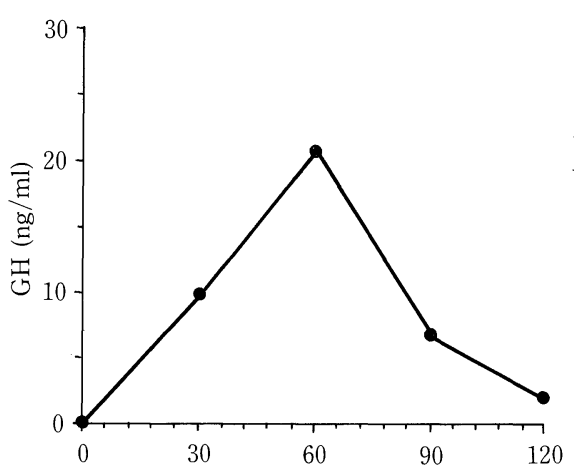

$\mathrm{C}$
$\mathrm{B}$

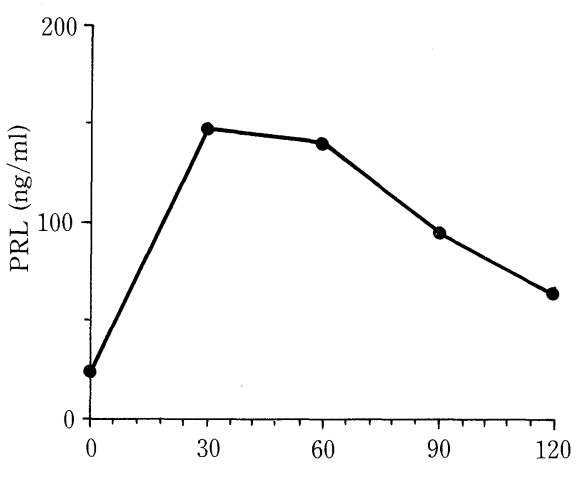

$\mathrm{D}$
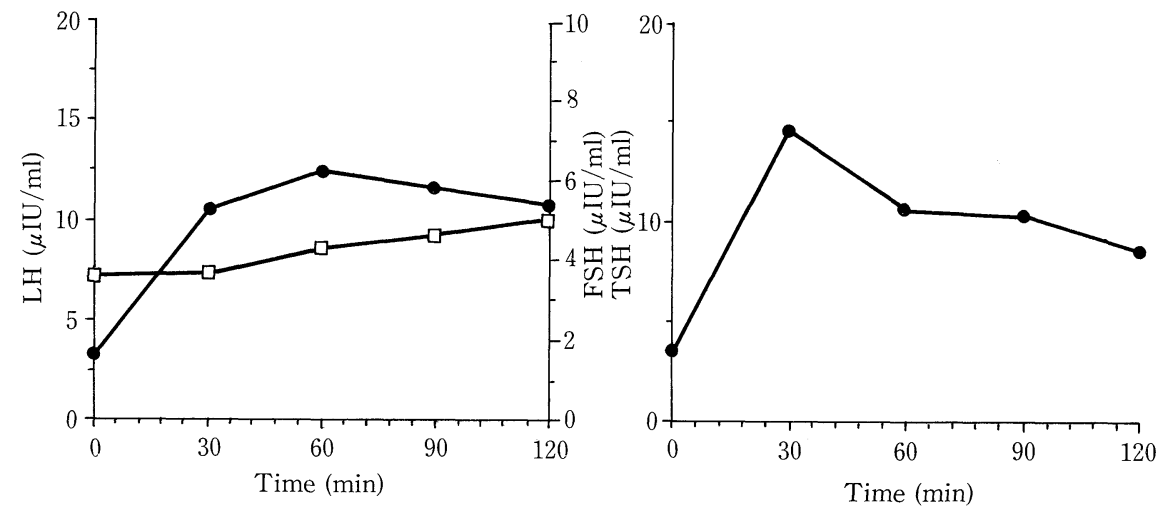

Figure 4. Arginine, LHRH and TRH loading tests. A) Modulation of GH, B) Modulation of PRL, C) Modulation of LH (closed circle) and FSH (open square), D) Modulation of TSH.

gland. Prolonged adrenal insufficiency due to conventional but inappropriate hydrocortisone replacement may cause secondary hyperplasia or adenoma of the pituitary gland (2-9). Alternatively, temporary pituitary adrenocortical failure may occur in an ACTH-producing adenoma. Such cases may have spontaneous Nelson's syndrome or Cushing's disease without hypercortisolism (1).

The present case already showed abnormal high levels of ACTH in the morning when he was diagnosed with Addison's disease and was treated with $30 \mathrm{mg}$ hydrocortisone for over 30 days. Systemic pigmentation apparent for about ten years, and enlargement of adrenal glands suggested mild prolonged adrenal insufficiency, which, in turn, may have induced secondary hyperplasia or adenoma. This resembles the first hypothesis. A similar case has been reported previously (8), but the ACTH response to dexamethasone in the present case was different.

Hydrocortisone was less effective than dexamethasone in suppressing ACTH the next morning; $0.25 \mathrm{mg}$ dexamethasone is equivalent to $7 \mathrm{mg}$ hydrocortisone. Since dexamethasone has a longer half-life than hydrocortisone, low-dose dexamethasone did suppress ACTH in the morning. Regulation of ACTH secretion in the present case was not completely autonomic. Endocrinologically, ACTH-producing hyperplasia or adenoma in Addison's disease show some degree of autonomy, and may be classified into two types, according to the response of ACTH to dexamethasone. In the first type, ACTH is not completely suppressed by $8 \mathrm{mg}$ dexamethasone/day $(4,8)$. This type resembles Nelson's syndrome. In the second type, ACTH is suppressed by hydrocortisone or $8 \mathrm{mg}$ dexamethasone/day (3, $4,6,7)$, which may be hyperplasia. Transsphenoidal surgery has been performed in a few patients $(3,9)$. The histological diagnosis is difficult to confirm. In an operated case of pituitary hyperplasia secondary to Addison's disease, administration of $8 \mathrm{mg}$ dexamethasone/day suppressed ACTH (9). In usual cases of Addison's disease, ACTH was suppressed by $2 \mathrm{mg}$ dexamethasone/day (4). The response is similar to the second type. Autonomy in the second type is less than the first type. From these data, the present case is more likely to be the second type, namely pituitary hyperplasia.

In the present case, the pituitary hormones except for FSH responded well to the corresponding challenges such as arginine, LHRH and TRH loading tests, indicating that other endocrine cells in the pituitary gland were preserved. A poor response of plasma ACTH to CRF has been reported in pituitary hyperplasia or adenoma in Addison's disease $(8,9)$. The response pattern in our case is consistent with previous reports. 
Miyabo et al reported that ACTH does not respond to CRF in the pre-operative state in pituitary hyperplasia secondary to Addison's disease. However, ACTH response to CRF became normal in the post-operative state. The excised portion of the pituitary gland was refractory to CRF (9). Shibasaki et al speculated that an ACTH producing tumor might lose receptors to CRF when it becomes adenomatous (10).

A few reports of similar cases have shown enlargement of the sella turcica on tomography (6), however, these did not employ MRI. In our case the right side of the pituitary gland was enlarged with a slightly lower signal than normal in T1 weighted images. The lesion had poor enhancement by Gd-DTPA, suggesting pituitary hyperplasia or adenoma. Since the pituitary lesion was small and no neurological signs or symptoms were detected, transsphenoidal surgery was not performed. Feek et al reported that 4 of 12 patients with Addison's disease, who were treated conventionally, showed elevated basal plasma ACTH concentrations, which were partially suppressed by oral administration of either $20 \mathrm{mg}$ hydrocortisone or $25 \mathrm{mg}$ cortisone acetate (11). If MRI is performed in such cases, pituitary abnormality may be detected with more frequency.

On admission, the present patient had typical symptoms and signs of Addison's disease. Diagnosis was definite from the clinical data. $20 \mathrm{mg}$ hydrocortisone was already administered when he was transferred to our hospital. Therefore, a daily profile of ACTH and ACTH response to CRF on cessation of medication were not performed.

Insufficient therapy for Addison's disease seems to induce pituitary hyperplasia or adenoma formation. Combination therapy to mimic the normal circadian rhythm of cortisol is necessary to prevent secondary hyperplasia or adenoma (5). Dexamethasone $(0.25 \mathrm{mg})$ at night to inhibit the nocturnal rise of ACTH secretion was effective in another reported case (6). Here, sufficient hormonal replacement improved pigmentation and suppressed further expansion of the sella turcica. Regression of systemic pigmentation and suppression of sella turcica expansion were observed after six months of the combination therapy in this case.

\section{References}

1) Dexter RN, Orth DN, Abe K, Nicholson WE, Liddle GW. Cushing's disease without hypercorticosolism. J Clin Endocrinol Metab 30: 573, 1970.

2) Krautli B, Muller J, Landolt AM, von Schulthess F. ACTH-producing pituitary adenomas in Addison's disease: two cases treated by transsphenoidal microsurgery. Acta Endocrinol (Copenh) 99: 357, 1982.

3) Aanderud S, Bassoe HH. A pituitary tumour with possible ACTH and TSH hypersecretion in a patient with Addison's disease and primary hypothyroidism. Acta Endocrinol (Copenh) 95: 181, 1980.

4) Jara-Albarran A, Bayort J, Caballero A, et al. Probable pituitary adenoma with adrenocorticotropin hypersecretion (corticotropinoma) secondary to Addison's disease. J Clin Endocrinol Metab 49: 236, 1979.

5) Dluhy RG, Moore TJ, Williams GH. Sella turcica enlargement and primary adrenal insufficiency. Ann Intern Med 89: 513, 1978.

6) Himsworth RL, Lewis JG, Rees LH. A possible ACTH secreting tumour of the pituitary developing in a conventionally treated case of Addison's disease. Clin Endocrinol (Oxf) 9: 131, 1978.

7) Clayton R, Burden AC, Schrieber V, Rosenthal FD. Secondary pituitary hyperplasia in Addison's disease. Lancet 2: 954, 1977.

8) Yanase T, Sekiya K, Ando M, Nawata H, Kato K, Ibayashi H. Probable ACTH-secreting pituitary tumour in association with Addison's disease. Acta Endocrinol (Copenh) 110: 36, 1985.

9) Miyabo S, Miyanaga K, Kimura K, Kishida S, Nakai T, Kubota N. Inappropriate secretion of adrenocorticotropin from corticotroph hyperplasia in a case of Addison's disease. Jpn J Med 29: 38, 1990.

10) Shibasaki $T$, Nakahara M, Shizume K, et al. Pituitary adenomas that caused Cushing's disease or Nelson's syndrome are not responsive to ovine corticotropin-releasing factor in vitro. J Clin Endocrinol Metab 56: 414, 1983.

11) Feek CM, Ratcliffe JG, Seth J, Gray CE, Toft AD, Irvine WJ. Patterns of plasma cortisol and ACTH concentrations in patients with Addison's disease treated with conventional corticosteroids replacement. Clin Endocrinol (Oxf) 14: 451, 1981. 